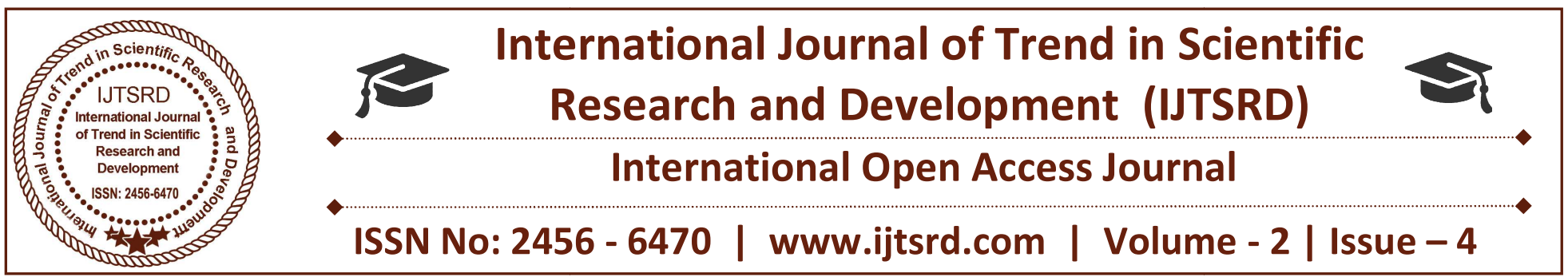

\title{
Floriculture using IoT in India
}

\author{
Puneeth $\mathbf{S}^{1}$, Vijeth A Belle ${ }^{2}$, Manjunath $\mathbf{C} \mathbf{R}^{3}$, Soumya $\mathbf{K} \mathbf{N}^{4}$ \\ ${ }^{1,2}$ B.Tech Final Year, ${ }^{3}$ Associate Professor, ${ }^{4}$ Assistant Professor \\ ${ }^{1,2,4}$ Department of Information Science \& Engineering, ${ }^{3}$ Department of Computer Science \& Engineering \\ School of Engineering \& Technology - Jain University \\ Bangalore, Karnataka, India
}

\section{ABSTRACT}

In India agriculture has major value and there is much importance given to it as we are being the world's largest producer of wheat and rice. India has a word to say for farmers that "Farmers are the backbone of our country". As India is basically dependent on agriculture we have adopted the vintage level methods in cultivating the crops so in this report we can find the smart technologies present in agriculture that one can adopt to get the best results in the crops and to earn profit in larger quantity. This paper we are using some technologies like cloud storage, Internet of things and image processing. The cultivators have to start doing plantation after that robot is let into the fields and checks for the growth of crops. This is a movable robot where it moves around the farm and finds the infected plant, take a picture of it and send it to the owner and perform some required action to keep it healthier by supplying essential nutrients. All the data which is obtained while doing inspection are stored in cloud for later purposes. Internet is main medium which keeps contact with robot, sensors and cloud data storage. Camera is used in the robot to take pictures of infected plants and normal plants and also helps in informing the owner of actions taken to improve the plants health which leads in getting better yield and better profit to the farmers.

Keywords: ripening effect, supplying nutrients, Image Processing for ripeness detection, Irrigation

\section{INTRODUCTION}

India is an agricultural country and there's a saying "Farmers are the backbone of our country" also India has the highest income rate in farming with import and export of vegetables grown in our territory, but nowadays nobody wants to be a farmer. It's high time that we make agriculture a parallel industry in India. Because of this reason smart IT technologies are needed to migrate from conventional agriculture methods to contemporary technologies so that one can control the cost, maintenance and monitoring performance of agriculture. Satellite and aerial imagery plays a main role in modern agriculture. Precision agriculture sensor monitoring network is used greatly to measure agriculture-related information like temperature, humidity, soil $\mathrm{PH}$, soil nutrition levels, water level etc. So, with IOT farmers can remotely monitor their crop and equipment by phones and computers. Internet of things helps various sensors to send data over the internet in a near real time manner. IT systems can work on this realtime data and notify users to take quick corrective actions like when some abnormal conditions are detected thus it helps in freeing up humans from doing the continues monitoring. New farmers are coming without any knowledge of soil characteristics they also face problems like insufficient soil testing labs are not available properly in the states of the country. So to solve this problem IOT is the solution which helps in collecting the data from the agriculture field and by taking the required action that in turn reduces the work of the farmer and results in getting better yield results. 
Irrigation is the process of giving required amount of water to the plants which are in need of water to grow the plants efficiently and healthily at the required intervals of time. Irrigation helps in maintaining the landscapes with respect to the soil and water content available in that region, growing more and more number of agricultural crops as per the requirements, revegetate the disturbed soil land in dry areas also during the time period of less rainfall.

It is the process which helps in maintaining the balance between the rotations of crops, maintain $g$ the efficient nutrients available in the soil surface, frost protection is included and it prevents the soil consolidation.

Irrigation includes various types of the system like

- Drip Irrigation

- Sprinkler Irrigation

- Surface Irrigation

- Micro-Irrigation and so on.

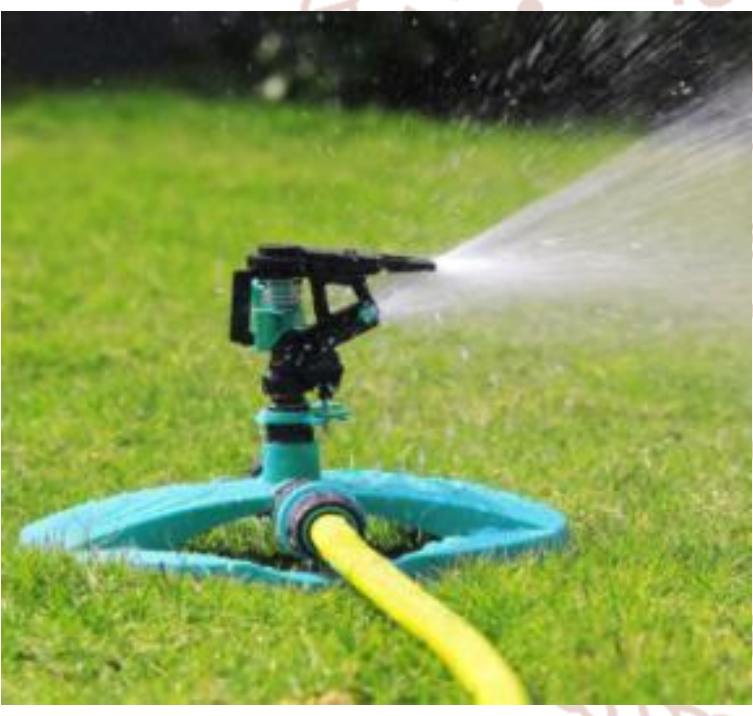

Fig 1.1: Manual Irrigation

Irrigation is latest technology which has evolved nowadays and it gives the necessary amount of water to the plants. For irrigation to happen the farmers can use the water sources like ground water, rivers, lakes, reservoirs, recycled water. The rain water harvesting water is not considered in this because it is not a form of irrigation and the water which are stored over there are runoffs from rooftops or unused lands

The Efficiency of the irrigation is calculated in terms of
- Field Water Efficiency (\%) = (Water Transpired by Crop $\div$ Water Applied to Field) $x \mathbf{1 0 0}$

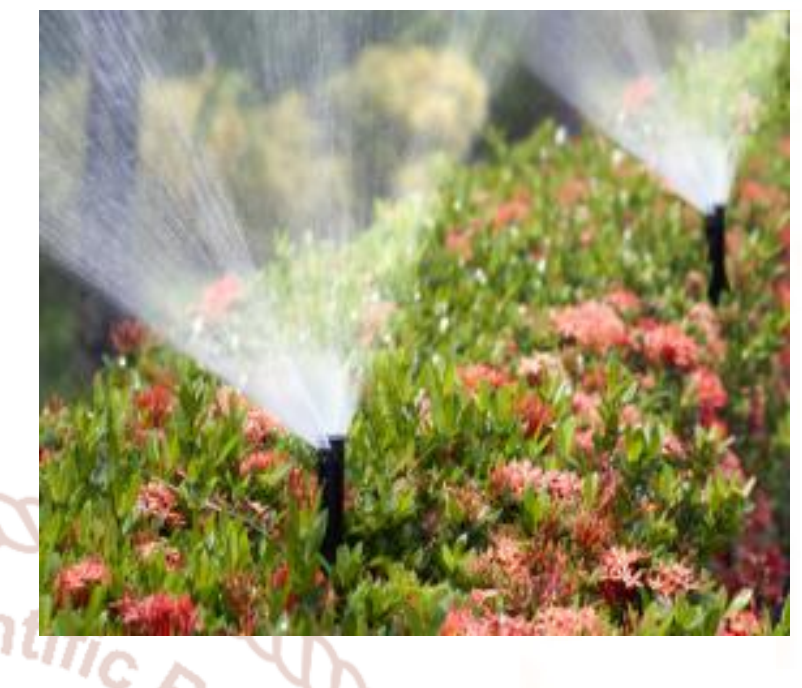

Fig 1.2: Sprinkler Irrigation - Flowers

\section{Background Work}

The various methods in irrigation for plants are:

A. A plant's leaf is taken care the most because it is the main thing which can judge the plant's health based on the nutrients supplied to it also the decaying of the leaf is a sign of showing the decaying of the plant and those plants are the one's which are needed to be taken care of so this paper is concentrating on the plant's health by collecting the reports of photosynthesis and has come out with constructing algorithm.

Leaf image detection is important is plant's health so a new algorithm is done to find the health of the plant where the algorithm is an dual channel PCNN and HIS is present. PCNN is used here for the first time for image processing and detection. The methods which are proposed in this paper is flexible and more suitable on the leaf health detection. This concept is only adaptive so far which deals with the leaf of an image which takes the image very clearly which helps in future studies. [1]. 


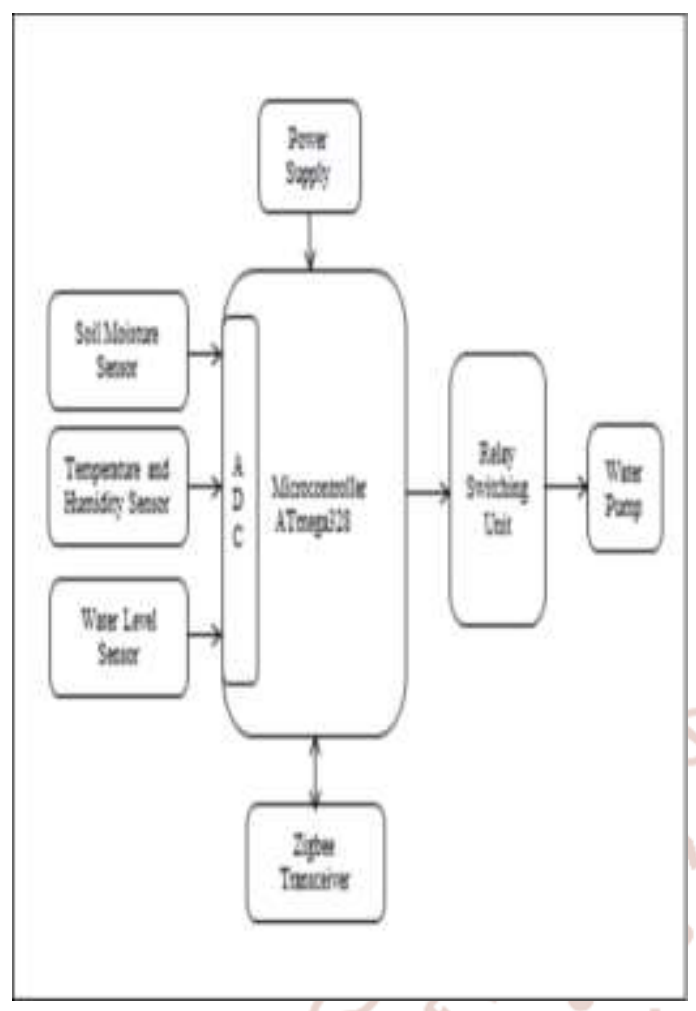

Fig 2.1: System Design

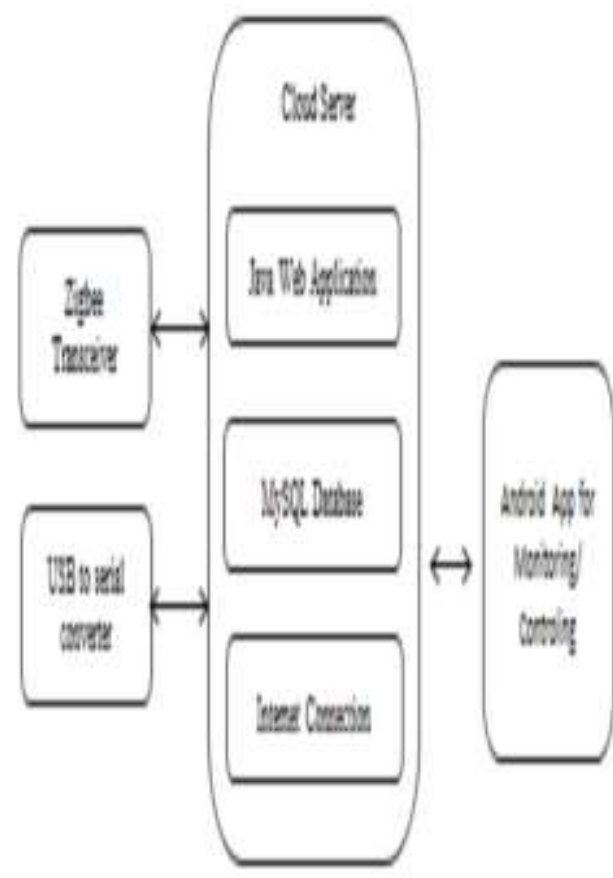

Fig 2.2: Cloud server connecting API
B. A plant's health and the communication is concentrated in this paper where here they are concentrating on the farming by using the smart technology based on wired and wireless communication. The proposed association in this report is a shrewd homestead wired/radio set framework with thickening - server - database and outer control structure. A ceasing point may survey the fundamental purposes of the paper whats's more, by applying a straightforward answer for the second hardship that can happen in radio correspondence, the intermodule topic trade has been effectively performed and by applying an institutionalized message trade technique that can be connected as a current related specialized field, the likelihood of extending the innovation covering in the IOT field can be affirmed. As correspondence between objects is required to be the beginning stage for mechanical motorization, natural and developing information gathered from the proposed framework can be normal a fundament for future huge information cultivating and counterfeit consciousness farming. [2].

C. A development application using remote sensor organizes for crops checking in the field. These frameworks completely furnished with two sorts of sensor hubs to gauge moistness, temperature, and a picture detecting hub to analyse data by taking pictures of harvests. Parameters assume a vital part to take a decent choice to make the product solid inside a timeframe. The traits are temperature, pictures and dampness. By following these strategies, we can accomplish high solidness of sensors with low utilization of energy [3]

D. There have been two intellectual capacities in this undertaking i.e. simulacrum handling and the 4 wheeled robots. This is a self-governing robot which development in a stipulated plan and taps the photographs of the plants and exchanges it to the server from where the MATLAB takings the photo and investigations it for sickness. The calculation utilizes room access to understand the same logical reasoning when done through ksubstance. So k-means and division issue nearly a similar measure of fourth measurement is more precise and simple to do assist 
E. For futurity creating, it can be produced for the expansive scale framework Also, the framework can be coordinated with different sensors like compost, a signal for adversaries, and can check the gauge of soil for a specific sort of yield development. Notwithstanding, some specialized and profession issues should be tended to in keen cultivating space of a capacity for the IOT-based creations and serving for producer. [5]

F. This bit of work outline and actualize a savvy NFT hydroponics cultivate utilizing induction from Bayesian Network. The sensor organize made out of $\mathrm{pH}$, light force, electrical conductivity piss temperature and relative nugginess detecting component were utilized to accumulate information from the ranch. The information got from the detecting component are psychological activity and are sent to an IOT stage. Actuators, for example, water pump, result pump, humidifier and light starting point were activated so as to change the frameworks parametric amount. Savvy cultivating was coordinated with Net of Things (IOT) by investigating the huge measure of information sent from the sensors. These datasets assembled for just about one month were utilized to produce BNs which at that point performs prescient investigation that gives yield conclusiveness to self-rulingly control the framework. Two sites were conveyed for wake, observing and restriction the actuator from the hydroponics cultivate. It is inferred that the stomach yielded from utilizing the programmed control is superior to anything the gather yielded from manual of arms control due to registered pick up contrast between $20 \%$ to LX $\%$ for all parameters used to assess great quality product . Because of genuine numberized ongoing information programmed procurement and information investigation of hydro phonics cultivate parameters and organic data, the planter can accomplished great financial and natural advantages, and the considerable essentialness to the advancement of present day farming data based knowledge benefit . Later on, to adequately enhance the framework, the information assemble task must be longer as bigger information would have create better for information examination. [6].
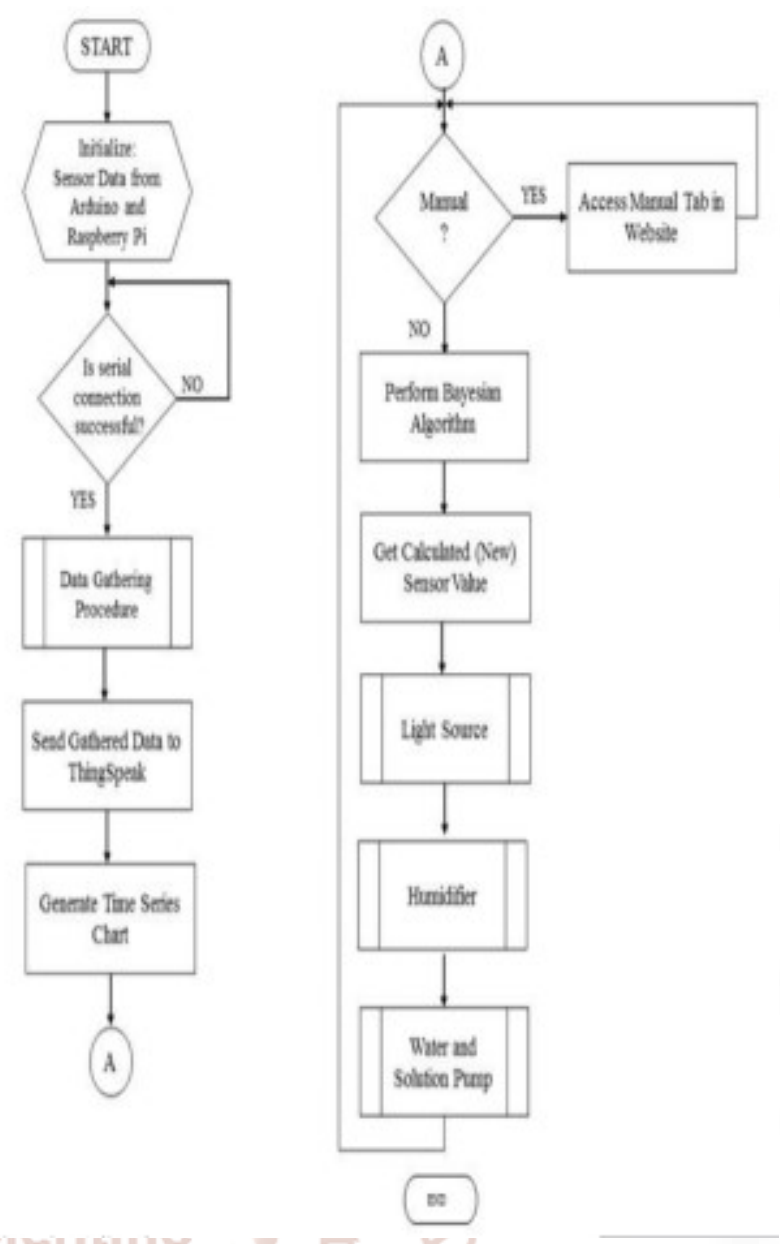

Fig 2.3: Flow Diagram

\section{Comparative Study}

India is known for agriculture and there is a word said in the country that "Farmers are the backbone of the Nation". India is the second largest producer of wheat and rice. It is the third largest producer for the pulses, several dry fruits, coconut, roots and tuber crops also $18 \%$ of India's gross domestic product is dependent on agriculture where in it gives $50 \%$ employment workforce in the country. This is the main source of income to the country.

According to NASSCOM industry board there are 280 IOT start-ups in India where around 40 companies concentrates basically on the agriculture and these companies are the important players which are ramping up their capabilities in the area like the innovations happening in the sectors of Robotics, Smart irrigation, Agri-Drones and produce monitoring sensors and agri sensors. 


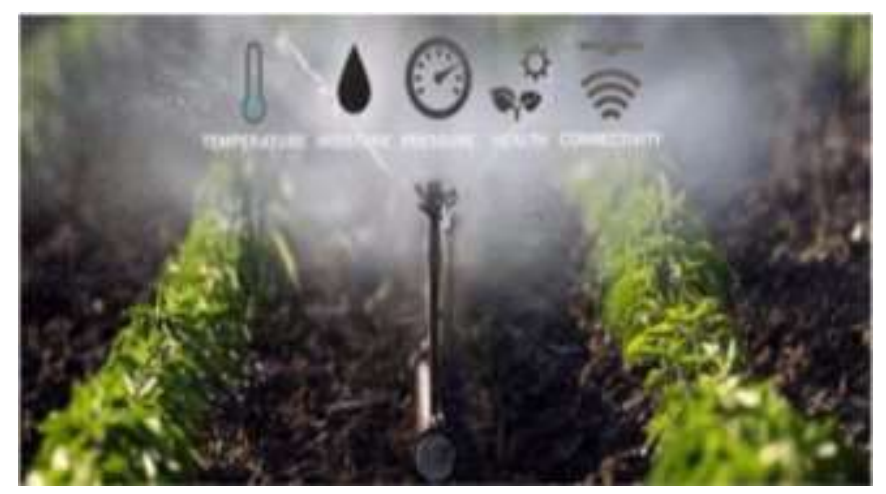

Fig 3.1: Smart Irrigation

used in this concept and the highest stands like this graph.

The graph is (Fig 3.3 Technology Used in IOT) shows the technology trends which increased gradually in the field of technology with respect to the devices.

\title{
Communications Technologies Used By loT Services \\ Q: What network ar communication technology or technologies do your senices or products employ?
}

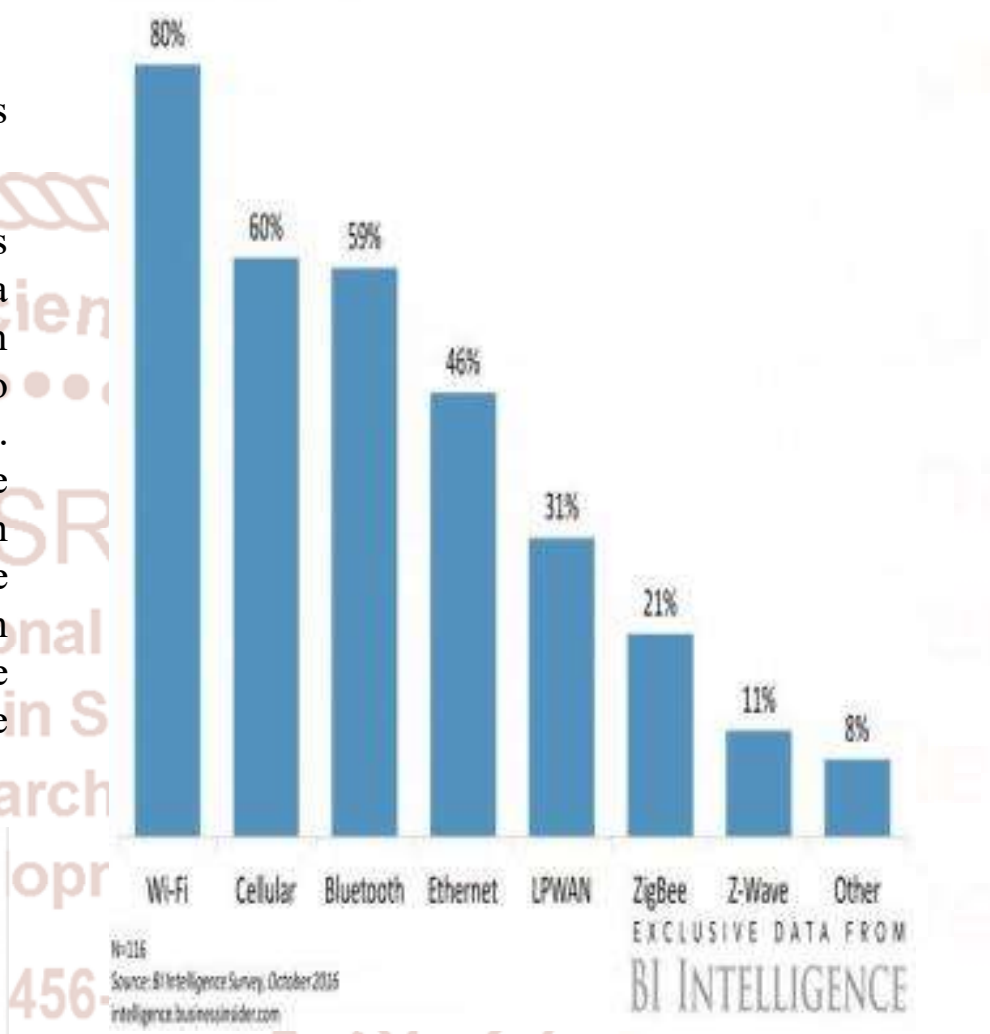

If the farmer is trying is trying to inculcate these ideas they can ensure a better outcome

in the farming. But the thing is there are many data's will be generated for a day and that turns out to be a big problem also to implement this idea in the farm land the project is very costly and the farmer has to bear all the expenses which he/she she gets from it. India even though it is known for the agriculture we lack in irrigation and implementing the technology in the fields. So, if the farmers are ready to use these ideas they can get better yield of their products with good profit. Refer to the Fig 3.2 which explains the data generated per day while using the IOT in the floriculture land.

\section{Estimated Amount Of Data Generated By The Average Farm Per Day}

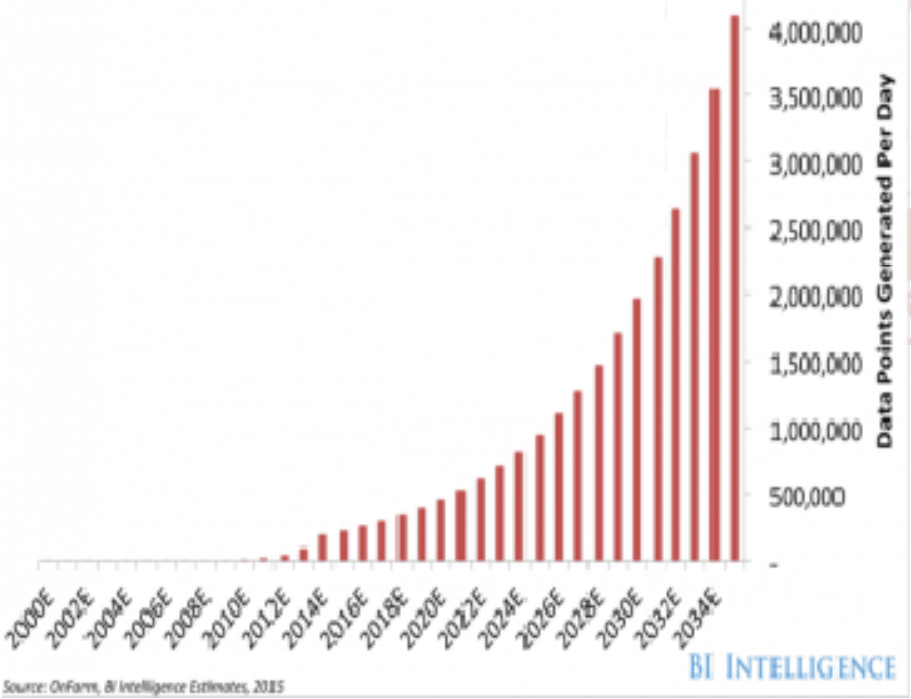

Fig 3.2: Data Generated per day

The Agriculture which is using technology in it like smart farming solutions they vary on the components used in it. There are several components which are

SR


sprinklers if required. During the harvesting time the machine will check for the health of the plant and also checks if the plant is ripen to be harvested .Periodically the machine collects information from its sensors about agriculture field area and then be logged and stored online using cloud computing and Internet of Things. It also removes the unwanted plants and insects in the soil that harms these flower plants and keeps the plant safe. It can also protect the plants from the wild animals that come into the farm by making loud unpleasant noise which scare the animals away. As the research have said that plants are also love human beings which has feelings and can recognize the changes happening around it as humans love music plants also love music and they grow faster and healthier so our system selects the pleasant music and plays it via speakers placed around the field so that plants can grow healthier.

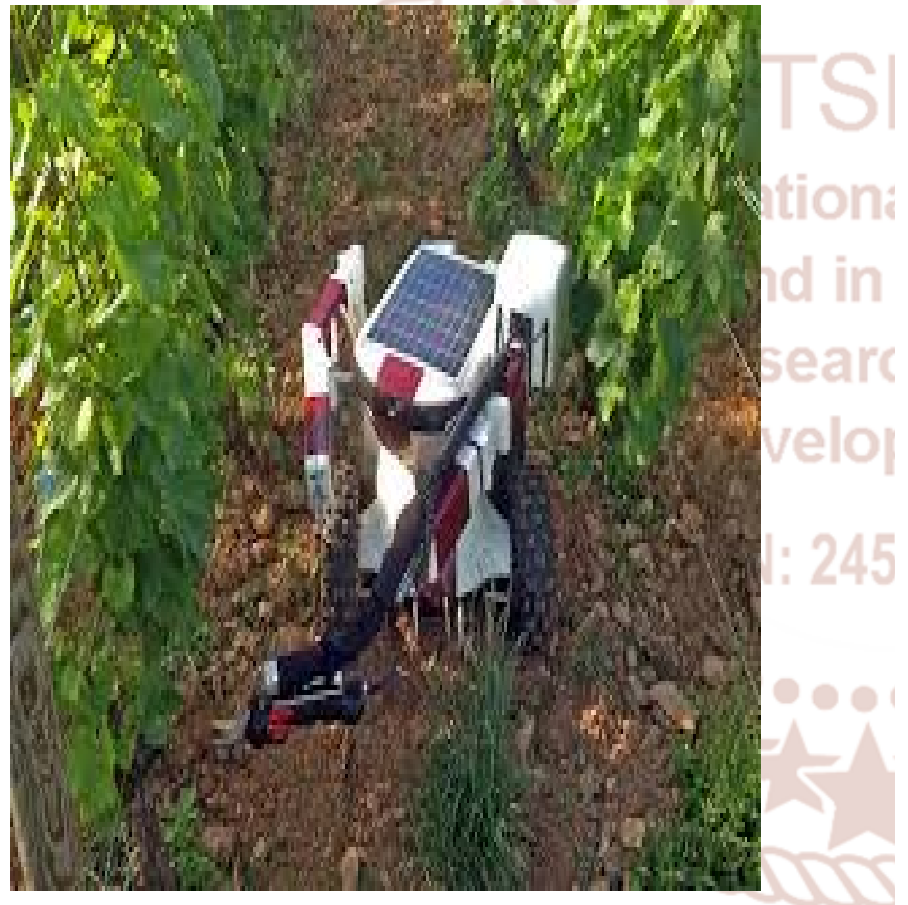

Fig 4.1: Robotics in Farming

The use of above mentioned techniques helps in conserving the energy resources of India through smart and efficient use of these resources. To illustrate a scenario, when a farmer needs to water his plants, he/she needs to do it manually which requires a lot of time and at times there might be an over usage of water which results in a waste-age of an essential resource. In such cases, smart agriculture can access information from the database such as soil moisture content, temperature, crop type which will help in watering the crops appropriately at the correct period of time.
These robots are movable in the farm field where they go around the field and finds the infected plants and takes the image of that plant and send it to cloud as well as to the owner then it performs the necessary action to improve the plants health also it manages to improve in the yielding the fruits or vegetables. These robots also take care of plants health by giving the necessary substantial's by supplying required nutrients, pesticides and some supplements which helps the plants in getting the better results.

Fig 4.2 System Architecture of model explains the construction of model with the flow of working according to the stages which will be followed from robot to camera then to sensors after that information will be stored in the database then necessary action will be taken on the plants by supplying necessary requirements and substantial's.

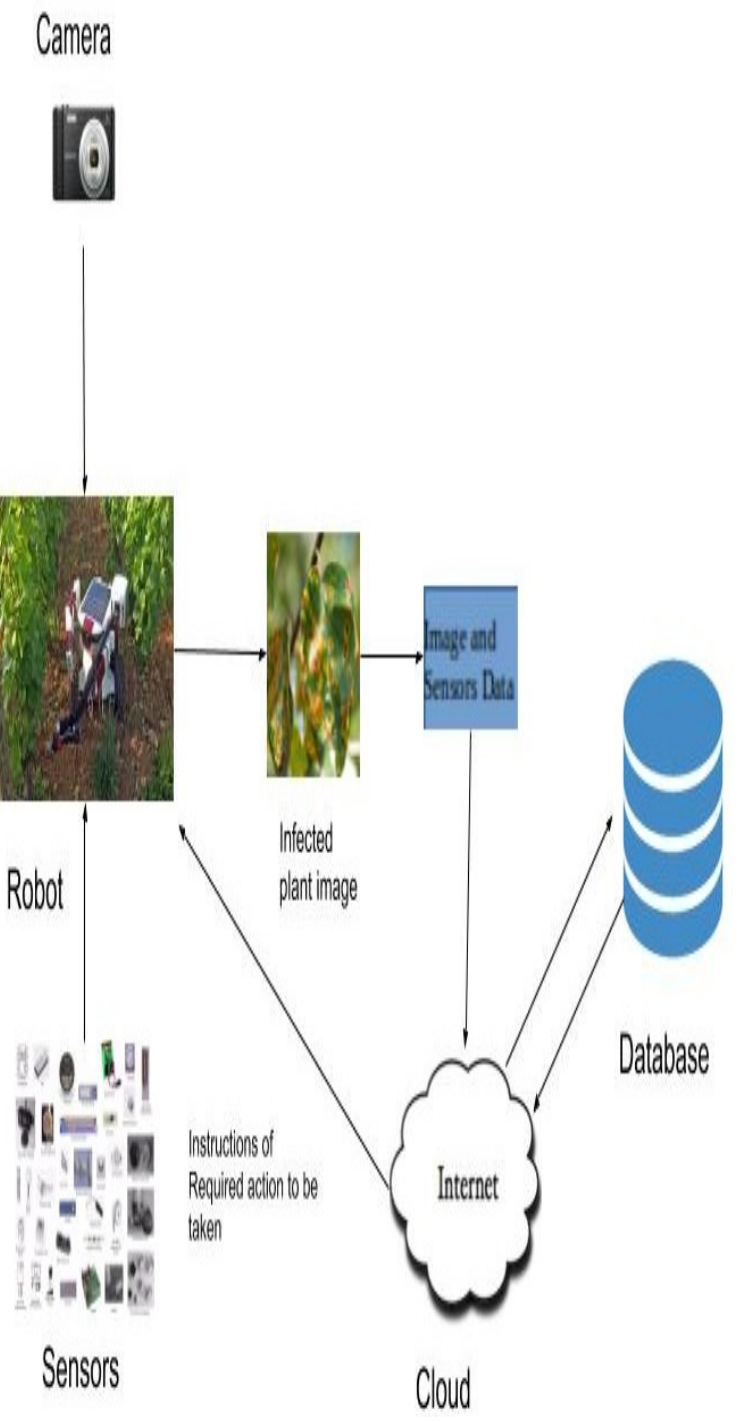

Fig 4.2: System Architecture of model 
International Journal of Trend in Scientific Research and Development (IJTSRD) ISSN: 2456-6470

\subsection{Advantages of Floriculture using IOT}

The following are the some of the advantages in the floriculture using IOT

\subsubsection{Expanded Creation-}

Improved gather treatment, for example, precise planting, watering, pesticide application and collecting specifically influences yield rates.

\subsubsection{Water Conservation -}

Climate expectation and domain dampness detecting component take into account water utilize when it's required.

\subsubsection{Brought down Operation Costs -}

\section{Computerizing intellectual} activity in planting, talk and gathering can diminish asset Consumption, human blunder and general cost.

\subsubsection{Expanded nature of generation -}

Dissecting yield quality and results in connection to treatment can Show famers how to alter procedures to enhance the nature of produce.

\subsection{Challenges of floriculture using IOT}

The following points are some of challenges one can expect while using this model

4.2.1 The model needs continuous power supply for to the servers which are connected to cloud systems.

4.2.2 The model needs continuous internet connection to make sure every information is carried out to cloud and the information is received to the user.

4.2.3 The model cannot get a proper image of a leaf if the sunlight is more as the leaf gets the sun reflection on it.

4.2.4 The model cannot take the complete image or the 360 degree angle of the plant as it will be surrounded by many plants.

\section{Conclusion}

The idea of this project is mainly concentrating on the health of plants as it looks on the factors like necessary elements which are required for the plants are supplied for the proper plant at a proper time by giving all the required supplements as it helps in increasing the production rate of the plants. This robot also moves around the farm for finding the sick/infected plants and checks whether is that a useful plant or not and if the model identifies that the plant is unnecessary over there it takes out that plant and cleans the surface. This project is just an idea of proposal where this can be done in small fields as it is just a developing concept. This idea depends on the farmer's mentality like how he/she uses this project in the farm. This depends on the type of soil, type of crops growing, method of growing the plants, quantity which can be accommodated in the land and so on. So, the famer's has to make sure that they are able to have a proper knowledge on this and implement in their field. If they are using this concepts in their field can they be able to manage to get better results or not will have to see in future?

\section{References}

Some references which are used to do this paper are:-

1) A new petiole detection algorithm based on leaf image Authors: Zhaobin Wang, Xu Zheng, Xiaugong sun, Hao Wang, Yide ma, Ying Zhu and Jianpeg Liu.

2) Implement Smart Farm with IoT Technology ChiyurlfYoon*, Miyoung Huh**, Shin-Gak Kang**, Juyoung Park**, Changkyu Lee** *Information and Communication Network Technology, University of Science Technology, Daejeon, Republic of Korea **Protocol Engineering Center, Electronics and Telecommunications Research Institute, Daejeon, Republic of Korea ycy7756@gmail.com, myhuh@etri.re.kr, sgkang@etri.re.kr, jypark@etri.re.kr, echkyu@etri.re.kr

3) IoT Based Smart Irrigation Monitoring And Controlling System Shweta B. Saraf NBN Sinhgad School of Engineering, gujrathishweta1@gmail.com, Dhanashri H. Gawali NBN Sinhgad School of Engineering, dhanashree.gawali@gmail.com

4) PLANT HEALTH ANALYSER Giriraja C.V., C. M. Siddharth, Ch. Saketa, M. Sai Kiran Department of Electronics \& Communication Engineering Amrita University Bengaluru Indiagiri_thanu@yahoo.com, maruthisiddharthc@gmail.com, saketha.jo@gmail.com, maganti.saikiran25@gmail.com

5) A Smart Hydroponics Farming System Using Exact Inference in Bayesian Network 
International Journal of Trend in Scientific Research and Development (IJTSRD) ISSN: 2456-6470

Melchizedek I. Alipio*, Allen Earl M. Dela Cruz $\dagger$, Jess David A. Doria $\ddagger$ and Rowena Maria S. Fruto§ Electronics Engineering Department, Malayan Colleges Laguna, Cabuyao City 4025 Philippines

Email:m.i.alipio@ieee.org,aemdelacruz@live.mcl. edu.ph,jdadoria@live.mcl.edu.ph and rmsfruto@live.mcl.edu.ph

6) An IoT Based Smart Solution for Leaf Disease Detection thoratapeksha77@gmail.com sangeeta.kumari@vit.edu D.Valakundenandkishor.valakunde@vit.edu
Computer Engineering Department, Vishwakarma Institute of Technology. Pune, India.

7) Nikesh Gondchawar, Prof. Dr. R. S. Kawitkar, "IOT based Smart Agriculture", 2016.

8) Srisruthi. S, N. Swarna, G. M. Susmitha Ros, Edna Elizabeth, "Sustainable Agriculture using Eco-friendly and Energy Efficient Sensor Technology", 2016.

9) PROJECT AGRO, "International Journal of research - Granthaalayah", 2017 by C R Manjunath, S chirag

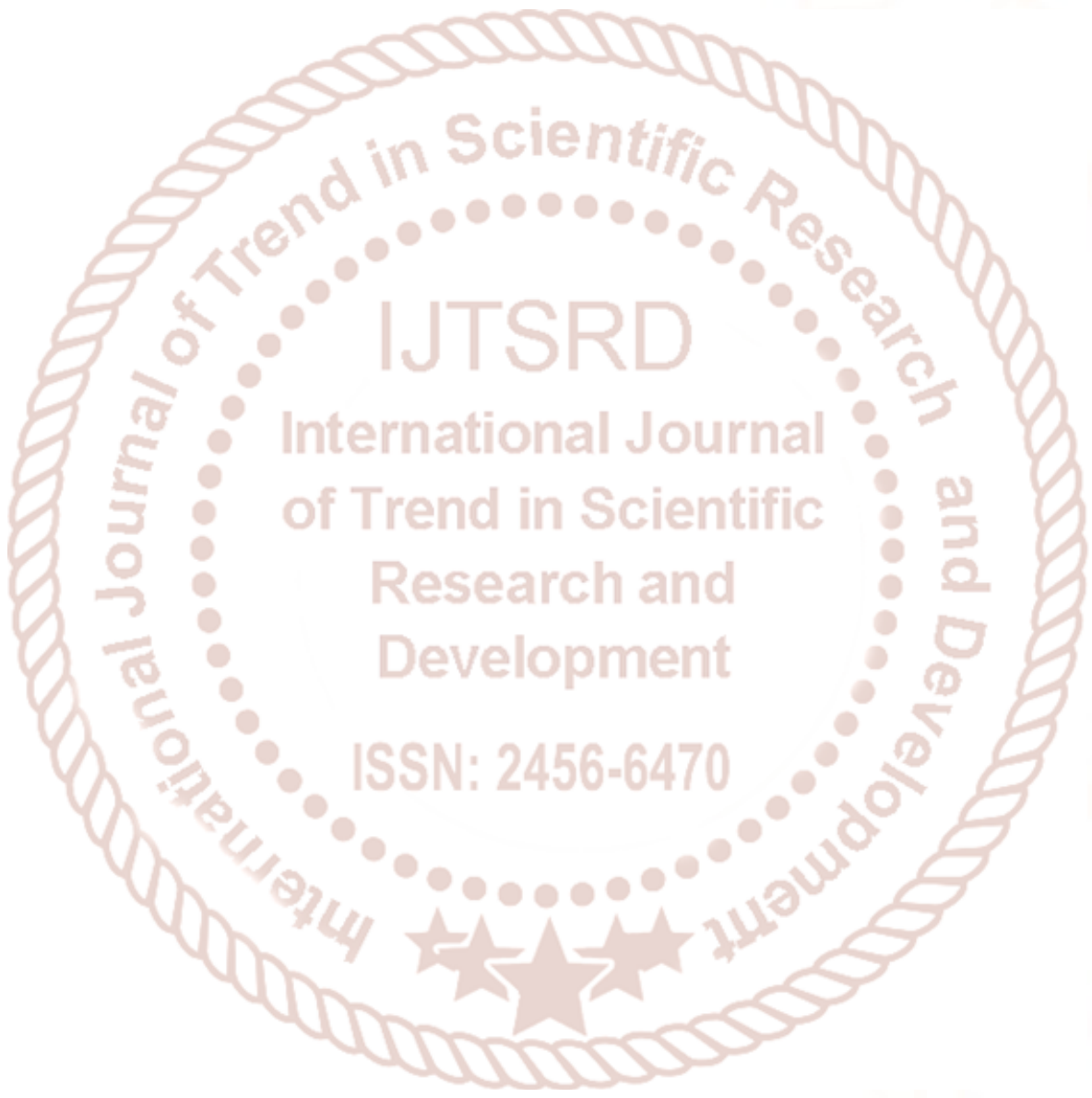

